\title{
The precision of epidemiological investigation of COVID-19 transmission in Shanghai, China
}

Ying Shi ${ }^{1,2,3}$, Hong-Lin Jiang ${ }^{1,2,3}$, Mei-Xia Yang ${ }^{4}$, Lin-Juan Dong ${ }^{5}$, Yue Chen ${ }^{6}$, Yi-Biao Zhou ${ }^{1,2,3^{*}}$ and Qing-Wu Jiang ${ }^{1,2,3}$

\begin{abstract}
Background: Shanghai had a local outbreak of COVID-19 from January 21 to 24 . Timely and precise strategies were taken to prevent further spread of the disease. We discussed and shared the experience of COVID-19 containment in Shanghai.

Process: The first two patients worked at two hospitals but no staff from the two hospitals were infected. The suspected case and his two close contacts were confirmed to be infected within $12 \mathrm{~h}$. The testing rate of individuals was low. The scope of screening was minimized to two related districts and the close contact tracing was completed within $12 \mathrm{~h}$, which were precise and cost-effective.
\end{abstract}

Conclusions: Active monitoring, precise epidemiological investigation and timely nucleic acid testing help discover new cases, minimize the scope of screening, and interrupt the transmission.

Keywords: COVID-19, Outbreak, Precision of epidemiological investigation, Shanghai

\section{Background}

A local transmission of severe acute respiratory syndrome coronavirus 2 (SARS-CoV-2) occurred in Shanghai in January 2021. Timely and precise prevention and control measures were taken to block the transmission and contain the epidemic. We discussed the strategies and measures of COVID-19 management in Shanghai, and shared the experience for controlling the small-scale outbreaks, especially in metropolis.

\section{Process of the outbreak in Shanghai}

A worker at the Shanghai Cancer Center affiliated with Fudan University had a routine coronavirus test on January 20, 2021, and was suspected of having COVID-19.

*Correspondence: z_yibiao@hotmail.com

${ }^{1}$ Fudan University School of Public Health, Building 8, 130 Dong'an Road, Shanghai 200032, China

Full list of author information is available at the end of the article
The health authorities immediately implemented a series of prevention and control measures including detailed epidemiological investigations and centralized quarantine of suspected close contacts. On January 21, the worker was confirmed to be the first new local case (Patient 1) of this outbreak. The second and third infected cases are his neighbor (Patient 2) and friend (Patient 3). Patient 4 is a relative of Patient 2. Patient 5 of the cluster resided in the hotel where Patient 3 worked, and a colleague of Patient 3 was confirmed to be infected with SARS-CoV-2 (Patients 6). They were all diagnosed on January 21, and connected to the subsequent patients.

Three newly infected cases were reported on January 22, relatives (Patients 7 and 8) of Patient 6 and a friend (Patient 9) of Patient 5. Three more cases occurred on January 23. Patient 10 lives in the same community with Patient 1 and was suspected to have a contact with Patient 1. Patient 11 is a relative of Patient 2. Patient 13 was reported on January 24, and is a relative of Patient original author(s) and the source, provide a link to the Creative Commons licence, and indicate if changes were made. The images or other third party material in this article are included in the article's Creative Commons licence, unless indicated otherwise in a credit line to the material. If material is not included in the article's Creative Commons licence and your intended use is not permitted by statutory regulation or exceeds the permitted use, you will need to obtain permission directly from the copyright holder. To view a copy of this licence, visit http://creativecommons.org/licenses/by/4.0/. The Creative Commons Public Domain Dedication waiver (http://creativeco mmons.org/publicdomain/zero/1.0/) applies to the data made available in this article, unless otherwise stated in a credit line to the data. 
2 as well. A total of 13 confirmed COVID-19 were all linked as shown in Fig. 1. The outbreak was controlled without a widespread transmission.

\section{Precision of epidemiological investigation}

The results of epidemiological investigation show that Patient 1 is a male and 56 years old, and he is a support crew in the Shanghai Cancer Center affiliated with Fudan University and lives in Huangpu Distinct, Shanghai. Patient 2 is a male and 53 years old, and he is a staff in Renji Hospital affiliated with Shanghai Jiaotong University, school of medicine. He lives in the same neighborhood with patient 1 . Patient 3 is a female and 48 years old, and she is a friend of Patient 1 . The epidemiological investigation also shows that the close-contact mode might be the route of transmission of this outbreak in Shanghai.

All the cases were in the early stage of COVID-19 infection. After diagnosed, they were transferred to Shanghai Public Health Clinical Center for further treatment, then had some symptoms such as fever, cough or expectoration. There are 12 cases with ordinary type and 1 case with light type, none cases with intensive or critical type. Three cases were more than 70 years old, and two of whom were 84 years old. They are all alive and some of cases had hypertension, diabetes or fat.

Shanghai acted quickly in response to this round of COVID-19 outbreak. Epidemiological investigation and aggressive contact tracing were instantly initiated when a suspected case with COVID-19 infection was found on January 20 at 3:00 pm. The suspected case and his two close contacts were confirmed to be infected within $12 \mathrm{~h}$. Usually, the overall test turnaround often exceeds $48 \mathrm{~h}$ for transporting samples to the laboratory and returning results to the originator [1]. All staff from the Shanghai Cancer Center Affiliated with Fudan University, where Patient 1 works, and the Renji Hospital, where Patent 2 works, were tested negative for SARS-CoV-2 during two rounds of screening [2]. The first round was conducted on January 21, and the second one on January 23. It indicates that strict protection measures are crucial in preventing healthcare workers from infection and containing the transmission. Other cases were all related to patients diagnosed on January 21 and they are friends, neighbors, relatives or coworkers, suggesting that this local transmission occurred mainly through close daily contacts. Reducing gatherings, wearing masks, and maintaining hand hygiene are the most important intervention measures [3].

As of January 24, 37592 individuals had been tested, only accounting for $5.78 \%$ of about total 650000 population of Huangpu District (reported in 2018), Shanghai. Only close contacts and residents in the same or surrounding communities and work places with infected cases were tested for the virus. The testing rate was lower as compared with other cities in China. While in another city, a total of 10.9 million people was screened, and the testing rate is nearly $100 \%$ [4]. It is necessary to monitor actively in high-risk groups such as health care staff. Hospitals in Shanghai have taken actions in preventive surveillance measures since 2020 . The precision of determining the scope of screening and rapid contact tracing at the early stage for an outbreak has so far been successfully applied for COVID-19 infection control, and is believed to be cost-effective. Shanghai has so far declared four medium-risk areas. These areas are small in size

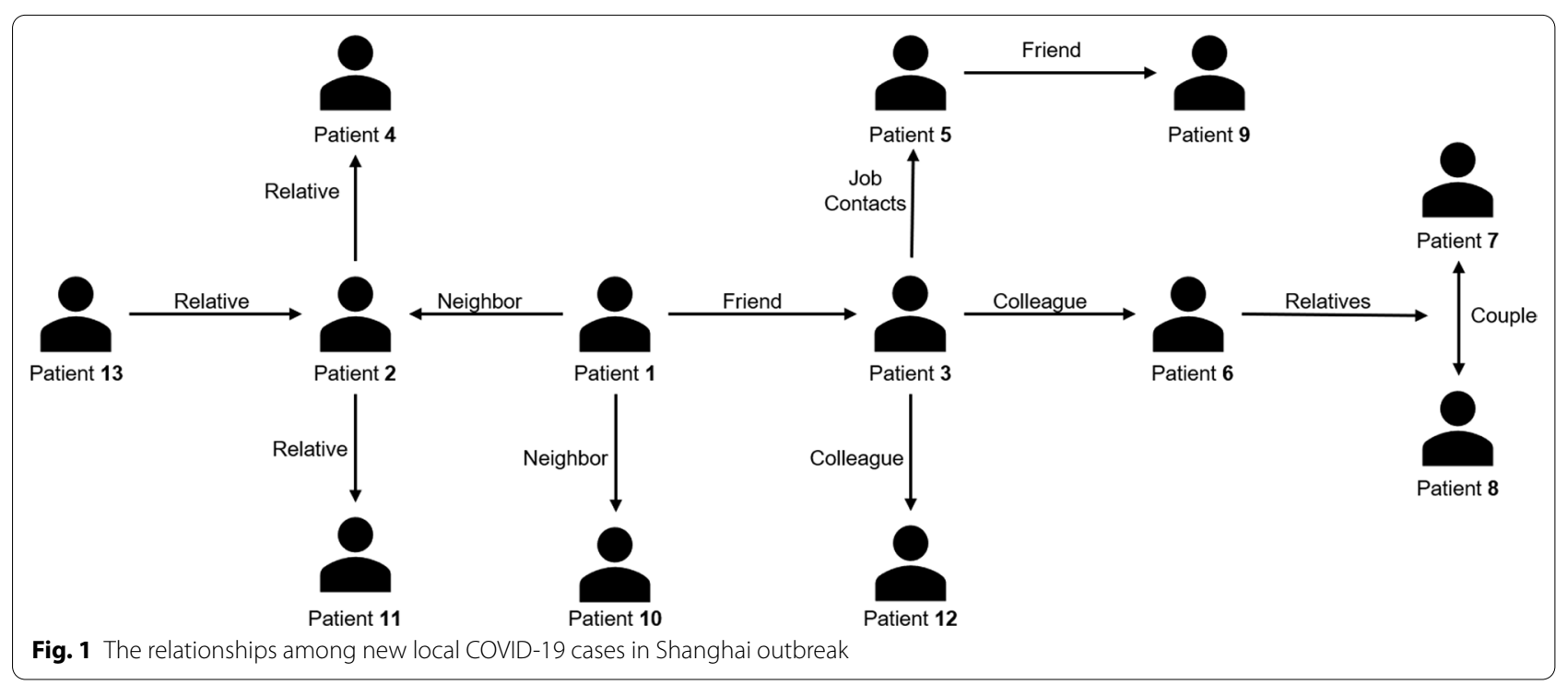


with only 7.3, 5.1, 3.0 and $5.1 \mathrm{~km}^{2}$ respectively. Residents in medium-risk areas are advised not to leave Shanghai, unless providing a negative nucleic acid test result within 7 days. It is necessary to accurately designate risk areas to contain the spread of the epidemic, but also reduce the impact on the life of residents and the waste of resources.

Systematic and standardized prevention and control measures are as follows. First, a measure for prevention is active monitoring. Regular surveillance and testing of high-risk populations may identify infected people before widespread transmission occurs [4]. Second, it is superior to conduct precise epidemiological investigation together with medical observation and nucleic acid testing. It is of great importance for high-quality epidemiological investigation, timely contact tracing and quarantine of highrisk individuals.

\section{Conclusions}

Active monitoring, precise epidemiological investigation and timely nucleic acid testing help to discover new cases, minimize the scope of screening, and interrupt the transmission. Mass-quarantine and mass nucleic acid testing could derail the economic vitality. It requires more precise and detailed strategies in the future, especially in metropolis.

Data were collected from the Shanghai Municipal Health Commission website (http://wsjkw.sh.gov.cn/) from January 21 to 24, 2021, including the number of daily new confirmed cases, the relationships among confirmed patients and the corresponding prevention and control measures. This article utilized government's open data for analysis.

\section{Abbreviations}

SARS-CoV-2: Severe Acute Respiratory Syndrome Coronavirus 2; COVID-19: Coronavirus Disease 2019.

\section{Acknowledgements}

Not applicable.

\section{Authors' contributions}

YS and QJ performed the conception of the study and YS wrote the manuscript; $H J$ revised it critically and polished the language; LD and MY made acquisition of data; $Y C$ revised the manuscript; $Y Z$ reviewed and edited the manuscript and performed final approval of the version to be submitted. All authors read and approved the final manuscript.
Funding

None.

Availability of data and materials

The dataset analysed during the current study are available from the Shanghai Municipal Health Commission website (http://wsjkw.sh.gov.cn/).

\section{Declarations}

\section{Ethics approval and consent to participate}

Not required. The data source was public, and the information of patients was altered to protect anonymity. The alterations do not distort scientific meaning.

\section{Consent for publication}

Not applicable.

\section{Competing interests}

None declared.

\section{Author details}

${ }^{1}$ Fudan University School of Public Health, Building 8, 130 Dong'an Road, Shanghai 200032, China. ${ }^{2}$ Key Laboratory of Public Health Safety, Fudan University, Ministry of Education, Building 8, 130 Dong'an Road, Shanghai 200032, China. ${ }^{3}$ Fudan University Center for Tropical Disease Research, Building 8, 130 Dong'an Road, Shanghai 200032, China. ${ }^{4}$ Xuhui Center for Disease Control and Prevention, Shanghai, China. ${ }^{5}$ Community Healthcare Center of Bansongyuan Street, Huangpu District, Shanghai, China. ${ }^{6}$ School of Epidemiology and Public Health, Faculty of Medicine, University of Ottawa, 451 Smyth Road, Ottawa, ON K1H 8M5, Canada.

Received: 15 March 2021 Accepted: 21 April 2021

Published online: 05 May 2021

References

1. Beeching NJ, Fletcher TE, Beadsworth MBJ. Covid-19: testing times. BMJ. 2020;369:1403

2. S.M.H. Commission. In: Press conference on January 24. 2021. http:// wsjkw.sh.gov.cn/xwfb/20210124/11dbfc2cc9834074a1a81107da6c713f. html. Accessed 15 Apr 2021.

3. Wang Y, Zhang N, Lv H, Zhou Y. Preliminary analysis on the incidence trend of novel coronavirus pneumonia in Shanghai. Shanghai J Prev Med. 2020;32(02):142-6.

4. Xing Y, Gary WK, Hu X, Xing Q. Rapid Response to an Outbreak in Qingdao, China. New Engl JMed. 2020;383(23):129.

Ready to submit your research? Choose BMC and benefit from:

- fast, convenient online submission

- thorough peer review by experienced researchers in your field

- rapid publication on acceptance

- support for research data, including large and complex data types

- gold Open Access which fosters wider collaboration and increased citations

- maximum visibility for your research: over $100 \mathrm{M}$ website views per year

At $\mathrm{BMC}$, research is always in progress.

Learn more biomedcentral.com/submissions 